\title{
$\alpha$-Lipoic acid has anti-inflammatory and anti-oxidative properties: an experimental study in rats with carrageenan-induced acute and cotton pellet-induced chronic inflammations
}

\author{
Fehmi Odabasoglu $^{1 *}$, Zekai Halici ${ }^{2}$, Hayati Aygun ${ }^{3}$, Mesut Halici ${ }^{4}$, Fadime Atalay ${ }^{1}$, \\ Ahmet Cakir ${ }^{5}$, Elif Cadirci ${ }^{6}$, Yasin Bayir ${ }^{1}$ and Halis Suleyman ${ }^{2}$ \\ ${ }^{1}$ Department of Biochemistry, Faculty of Pharmacy, Ataturk University, 25240 Erzurum, Turkey \\ ${ }^{2}$ Department of Pharmacology, Faculty of Medicine, Ataturk University, 25240 Erzurum, Turkey \\ ${ }^{3}$ Department of Orthopedics and Traumatology, Faculty of Medicine, Kafkas University, Kars, Turkey \\ ${ }^{4}$ Department of Biochemistry, Faculty of Veterinary, Ataturk University, 25240 Erzurum, Turkey \\ ${ }^{5}$ Department of Chemistry, Faculty of Science and Art, Kilis 7 Aralik University, 79100 Kilis, Turkey \\ ${ }^{6}$ Department of Pharmacology, Faculty of Pharmacy, Ataturk University, 25240 Erzurum, Turkey \\ (Received 23 June 2010 - Revised 29 June 2010 - Accepted 5 July 2010 - First published online 15 November 2010)
}

\section{Abstract}

$\alpha$-Lipoic acid (ALA) has been termed the 'ideal' antioxidant, a readily absorbed and bioavailable compound capable of scavenging a number of free radicals, and it has been used for treating diseases in which oxidative stress plays a major role. The present study was designed to gain a better understanding for the positive effects of ALA on the models of acute and chronic inflammation in rats, and also determine its anti-oxidative potency. In an acute model, three doses of ALA $(50,100$ and $200 \mathrm{mg} / \mathrm{kg})$ and one dose of indomethacin $(25 \mathrm{mg} / \mathrm{kg}) \mathrm{or}$ diclofenac $(25 \mathrm{mg} / \mathrm{kg})$ were administered to rats by oral administration. The paw volumes of the animals were calculated plethysmometrically, and $0.1 \mathrm{ml}$ of $1 \%$ carrageenan (CAR) was injected into the hind paw of each animal $1 \mathrm{~h}$ after oral drug administration. The change in paw volume was detected as five replicates every $60 \mathrm{~min}$ by plethysmometry. In particular, we investigated the activities of catalase, superoxide dismutase (SOD), glutathione $S$-transferase (GST), glutathione peroxidase (GPx), glutathione reductase (GR), inducible NO synthase (iNOS) and myeloperoxidase (MPx), and the amounts of lipid peroxidation (LPO) or total GSH in the paw tissues of CAR-injected rats. We showed that ALA exhibited anti-inflammatory effects on both acute and chronic inflammations, and a strongly anti-oxidative potency on linoleic acid oxidation. Moreover, the administration of CAR induced oedema in the paws. ALA significantly inhibited the ability of CAR to induce: (1) the degree of acute inflammation, (2) the rise in MPx activity, (3) the increases of GST and iNOS activities and the amount of LPO and (4) the decreases of GPx, GR and SOD activities and the amount of GSH. In conclusion, these results suggest that the anti-inflammatory properties of ALA, which has a strong anti-oxidative potency, could be related to its positive effects on the antioxidant system in a variety of tissues in rats.

Key words: $\alpha$-Lipoic acid: Cotton pellets: Chronic inflammation: Carrageenan: Acute inflammation: Myeloperoxidase: Antioxidant enzymes: Inducible nitric oxide synthase

Inflammatory diseases such as rheumatoid arthritis, asthma and hepatitis are the major causes of morbidity in humans. Today, it is well known that chronic inflammation also leads to the development of cancer, CVD and neurodegenerative diseases. Oedema formation in the paw is the result of a synergism between various inflammatory mediators that increase vascular permeability and/or the mediators that increase blood flow. Several experimental models of paw oedema have been described. Carrageenan (CAR)induced paw oedema is widely used for determining the acute phase of inflammation. Histamine, 5-hydroxytryptamine and bradykinin are the first detectable mediators in the early phase of CAR-induced inflammation, whereas $\mathrm{PG}$ are detectable in the late phase of inflammation ${ }^{(1-5)}$

Abbreviations: ALA, $\alpha$-lipoic acid; CAR, carrageenan; CAT, catalase; DIC, diclofenac; GPx, glutathione peroxidase; GR, glutathione reductase; GST, glutathione $S$-transferase; IND, indomethacin; iNOS, inducible nitric oxide synthase; LPO, lipid peroxidation; MPx, myeloperoxidase; NOS, nitric oxide synthase; ROS, reactive oxygen species; SOD, superoxide dismutase.

Anti-inflammatory effects of the $\alpha$-lipoic acid on carrageenan-induced acute and cotton pellet-induced chronic inflammation models in rats and its relation with nitric oxide synthase activity. International Symposium on Drug Research and Development, 17-20 May 2007, Antalya, Turkey, p. 56.

*Corresponding author: Dr F. Odabasoglu, fax +90 442 2360962, email fodabasoglu@yahoo.com 
It is well known that the acute inflammatory process, in which vascular permeability increases and leucocyte migration occurs, involves inflammation mediators including neutrophil-derived active oxygen species and free radicals, such as $\mathrm{H}_{2} \mathrm{O}_{2}$ and superoxide, and the hydroxyl radicals, such as NO, PG and cytokines ${ }^{(3-5)}$. Polymorphonuclear leucocytes that are the first cells to arrive at the inflammatory site in the body release free oxygen radicals and free hydroxyl radicals ${ }^{(3-7)}$. On the other hand, in many physiological functions of the body and the pathogenesis of inflammation, ion exchanges between intracellular and extracellular areas have been identified. It has been reported that increased intracellular $\mathrm{Ca}$ ion stimulates inflammation events and Ca channel blocker drugs diminish these events ${ }^{(3-7)}$. However, the chronic inflammation model, induced by subcutaneous implantation of foreign bodies, is used commonly in experiments ${ }^{(3,5,8,9)}$. Chronic inflammation starts with the occurrence of proliferative cells ${ }^{(9)}$. These cells can be spread or can form a granuloma tissue. Inflammatory granuloma tissue is a typical example of chronic inflammation. On the other hand, granuloma formation is initialised by an antigen (for example, a cotton pellet). The cotton pellet stimulates the immune system, antibodies and production of IL. This stimulation results with the proliferation of lymphocytes and the formation of granulation tissue over the pellets ${ }^{(8,10)}$. Non-steroidal anti-inflammatory drugs and ulcers reduce granuloma tissue that is formed with cellular reactions by inhibiting granulocyte infiltration, while glucocorticoids do it by inhibiting fibrosis and macrophage function ${ }^{(5,8-10)}$.

Reactive oxygen species (ROS) including free radicals such as hydroxyl radicals $\left(\mathrm{OH}^{\circ}\right)$ or superoxide anions $\left(\mathrm{O}_{2}^{-}\right)$and non-free radical species such as $\mathrm{H}_{2} \mathrm{O}_{2}$ constantly cause lipid peroxidation (LPO) in tissues by attacking unsaturated fatty acids. Oxidative stress also plays an important role in the pathogenesis of many other diseases such as respiratory distress syndrome, rheumatoid arthritis, local or systemic inflammatory disorders, sepsis, diabetes, atherosclerosis and cancer ${ }^{(2,10-18)}$. On the other hand, aerobic organisms possess antioxidant defence systems including enzymatic and non-enzymatic antioxidants to combat the toxic effects of ROS. These antioxidants are superoxide dismutase (SOD), glutathione peroxidase (GPx), catalase (CAT), GSH, glutathione reductase (GR), tocopherols, vitamin $\mathrm{C}, \boldsymbol{\beta}$-carotene, vitamin A and flavonoids. Myeloperoxidase (MPx), found in azurophilic granules of mammalian neutrophils and in human monocytes, is involved in microbial killing and inflammatory tissue damage, and neutrophil infiltration into gastric mucosal tissues is a critical process in the pathogenesis of gastric lesions induced by non-steroidal anti-inflammatory drugs and ulcers ${ }^{(8,19)}$. NO, enzymatically produced from NO synthase (NOS), first discovered in the vascular endothelium, plays many important roles in health and diseases. NOS is present in several isoforms in a large number of cells besides endothelial cells, such as the constitutive

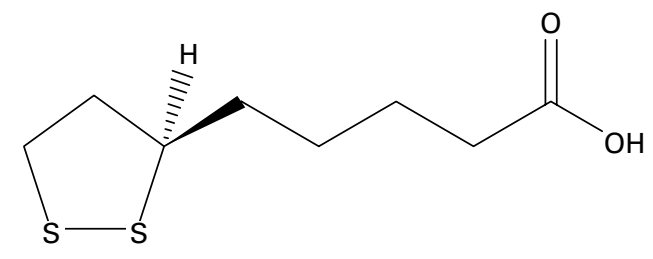

Fig. 1. Chemical structure of $\alpha$-lipoic acid.

endothelial NOS and neuronal NOS under physiological conditions and inducible NO synthase (iNOS), which is induced by cytokines under pathophysiological conditions $^{(4,11,16-18)}$.

$\alpha$-Lipoic acid (ALA, Fig. 1) is a naturally occurring essential co-enzyme in mitochondrial multienzyme complexes catalysing the oxidative decarboxylation of $\alpha$-keto acids such as pyruvate, $\alpha$-ketoglutarate and branched-chain $\alpha$-keto acid $^{(20-22)}$. ALA has been shown to combat oxidative stress by quenching a variety of intracellular $\operatorname{ROS}^{(21,22)}$. In addition to ROS scavenging, ALA has also been shown to be involved in the recycling of other cellular antioxidants including vitamins $\mathrm{C}$ and $\mathrm{E}$, and $\mathrm{GSH}^{(23)}$. ALA has been demonstrated to be effective in preventing pathology in various experimental models in which ROS have been implicated, such as ischaemia-reperfusion injury $^{(15)}$, diabetes ${ }^{(24)}$, hypertension ${ }^{(25)}$, radiation injury ${ }^{(26)}$ and HIV activation ${ }^{(27)}$. On the other hand, in cancer cells, ROS also play a crucial role in cell growth and apoptosis regulation. ALA and its reduced form, dihydrolipoic acid, have been shown to inhibit proliferation and induce apoptosis of several cancer and transformed cell lines, while being less active towards normal non-transformed cells ${ }^{(28)}$.

In the present study, we aimed to evaluate: (a) the reducing effects of ALA on acute (CAR induced) and chronic phases (cotton pellet granule) of inflammation, (b) the changes of LPO and antioxidant levels (SOD, GSH, CAT, glutathione $S$-transferase (GST), GPx and GR), and MPx and iNOS activities, as markers of acute inflammation, in paw tissues of rats and (c) in vitro antioxidant potency of ALA.

\section{Materials and methods}

\section{Animals}

A total of seventy-eight male Wistar rats, weighing 180-190 g, were provided from the Experimental Animal Laboratory of Ataturk University, the Experimental Animal Teaching and Research Center. The animals were housed in groups of five or six per cage for at least $5 \mathrm{~d}$ under controlled conditions of constant temperature/ humidity and exposed to a $12 \mathrm{~h}$ light-dark cycle ${ }^{(29)}$. Animals for acute inflammation experiments were assigned randomly to the control groups receiving either CAR $(0.1 \mathrm{ml}$ of $1 \%$ CAR per animal) or water and to the experimental groups receiving CAR plus ALA at doses of 50, 100 and $200 \mathrm{mg} / \mathrm{kg}$, indomethacin (IND) at a dose of $25 \mathrm{mg} / \mathrm{kg}$ 
and diclofenac (DIC) at a dose of $25 \mathrm{mg} / \mathrm{kg}$. Besides, the animals were grouped similarly to evaluate chronic inflammation via the cotton pellet-induced granuloma test. The experiments were conducted according to the ethical norms approved by the Ethics Committee of the Experimental Animal Teaching and Research Center (no: B.30.2.ATA.0.70/144-4).

\section{Chemicals}

All chemicals for laboratory experiments were purchased from Sigma Chemical (Munich, Germany). Other compounds were obtained from various sources: ALA was obtained from Life Time (Istanbul, Turkey), DIC (Myadren $50 \mathrm{mg}$ Tablet) was obtained from Fako (Istanbul, Turkey) and IND (Endosetin capsule) was obtained from Nobel (Istanbul, Turkey).

\section{Carrageenan-induced paw oedema in rats}

In this type of experiment, the effects of ALA and positive controls (IND and DIC) on CAR-induced paw oedema in rats were investigated ${ }^{(8)}$. The animals were divided into seven groups, each consisting of six rats (Table 1 and Fig. 2). ALA, CAR, IND and DIC solutions were prepared by dissolving in distilled water. Briefly, three doses of ALA $(50,100$ and $200 \mathrm{mg} / \mathrm{kg}$ ) and one dose of IND $(25 \mathrm{mg} / \mathrm{kg})$ and DIC $(25 \mathrm{mg} / \mathrm{kg})$ were administered orally to rats with the aid of gavages. The paw volumes of the animals were calculated plethysmometrically, and $0.1 \mathrm{ml}$ of $1 \%$ CAR was injected into the hind paw of each animal $1 \mathrm{~h}$ after the last dose. The change in paw volume was detected as five replicates every $60 \mathrm{~min}$ by plethysmometry. The anti-inflammatory potency of ALA was determined via comparison with the result obtained from the animals receiving equal volumes of positive controls (IND and DIC), CAR (control) and distilled water (negative control). The last group of animals (seventh group) was used for antioxidant enzyme research and is called the healthy group (no drug or CAR administration). The anti-inflammatory effects of these drugs were calculated by the following equation:

$$
\begin{aligned}
& \text { Anti-inflammatory activity (inhibition \%) } \\
& \quad=(1-D / C) \times 100
\end{aligned}
$$

where $D$ represents the percentage difference in paw volume after the administration of drugs to the rats, and $C$ represents the percentage difference of volume in the control groups.

\section{Biochemical analysis of carrageenan-induced paw oedema in rats}

Preparation of tissues homogenates. After the plethysmometric analyses, the activities of CAT, SOD, GST, GPx, GR, iNOS and MPx, and the amounts of LPO or total GSH in paw tissues of rat oedema were determined. To prepare the tissue homogenates, paw oedema tissues of each rat groups ( $n$ 6) were ground with liquid $\mathrm{N}_{2}$ in a mortar. The ground tissues $(0.5 \mathrm{~g}$ each) were then treated with $4.5 \mathrm{ml}$ of an appropriate buffer. The mixtures were homogenised on ice using an ultra-turrax homogeniser for $15 \mathrm{~min}$. Homogenates were filtered and centrifuged by using a refrigerated centrifuge at $4^{\circ} \mathrm{C}$. Then, these supernatants were used for the determination of the enzymatic activities. All the assays were carried out at room temperature as three parallel measurements.

Glutathione S-transferase activity. Total GST activity was determined as described by Habig \& Jakoby ${ }^{(30)}$ Briefly, the enzyme activity was assayed spectrophotometrically at $340 \mathrm{~nm}$ in a $4 \mathrm{ml}$ cuvette containing $0 \cdot 1 \mathrm{M}-\mathrm{PBS}$ (pH 6.5), 3 0mm-GSH, $30 \mathrm{mm-1-chloro-2,6-dinitrobenzene}$ and tissue homogenate. Enzyme activity was expressed as $\mathrm{nmol} / \mathrm{min}$ per $\mathrm{mg}$ protein.

Table 1. Effects of $\alpha$-lipoic acid (ALA), indomethacin (IND) and diclofenac (DIC) on carrageenan (CAR)-induced paw oedema (fourth hour) in rats $\dagger$

\begin{tabular}{|c|c|c|c|c|c|c|}
\hline \multirow[b]{2}{*}{ Treatment } & \multirow[b]{2}{*}{$n$} & \multirow{2}{*}{$\begin{array}{c}\text { Dose } \\
\text { (mg/kg body wt) }\end{array}$} & \multirow{2}{*}{$\begin{array}{l}\text { Paw volume before } \\
\text { inflammation }(\mathrm{ml})\end{array}$} & \multicolumn{2}{|c|}{$\begin{array}{l}\text { Difference between } \\
\text { paw volumes (ml) } \\
\text { at fourth hour }\end{array}$} & \multirow{2}{*}{$\begin{array}{l}\text { Anti-inflammatory } \\
\text { effect (inhibition \%)‡ }\end{array}$} \\
\hline & & & & Mean & SEM & \\
\hline CAR + ALA & 6 & 50 & 1.08 & 0.44 & 0.08 & $18 \cdot 5$ \\
\hline $\mathrm{CAR}+\mathrm{ALA}$ & 6 & 100 & $1 \cdot 1$ & $0.38^{*}$ & 0.01 & $29 \cdot 6$ \\
\hline CAR + ALA & 6 & 200 & 1.09 & $0.32^{\star \star}$ & 0.03 & $40 \cdot 7$ \\
\hline CAR + DIC & 6 & 25 & 1.02 & $0.30^{\star *}$ & 0.02 & $44 \cdot 4$ \\
\hline CAR + IND & 6 & 25 & 1.09 & $0.24^{\star *}$ & 0.02 & $55 \cdot 5$ \\
\hline Control (CAR) & 6 & - & 1.04 & 0.54 & 0.05 & - \\
\hline
\end{tabular}
(Mean values with their standard errors, $n 6$ )

$n$, Number of animals.

Mean values were significantly different when compared to that of the control group: ${ }^{\star} P<0.05$, ${ }^{\star \star} P<0.01$.

† Three doses of ALA $(50,100$ and $200 \mathrm{mg} / \mathrm{kg})$, and one dose of IND $(25 \mathrm{mg} / \mathrm{kg})$ or DIC $(25 \mathrm{mg} / \mathrm{kg})$ were administered to rats by oral administration. Three doses of the ALA-treated group and one dose of the IND- and DIC-treated groups were compared with the CAR group. The paw volumes of the animals were calculated plethysmometrically, and $0.1 \mathrm{ml}$ of $1 \%$ CAR was injected into the hind paw of each animal $1 \mathrm{~h}$ after oral drug administration.

$\ddagger$ Inhibition \% in paw volumes in relation to control (carrageenan) group. 


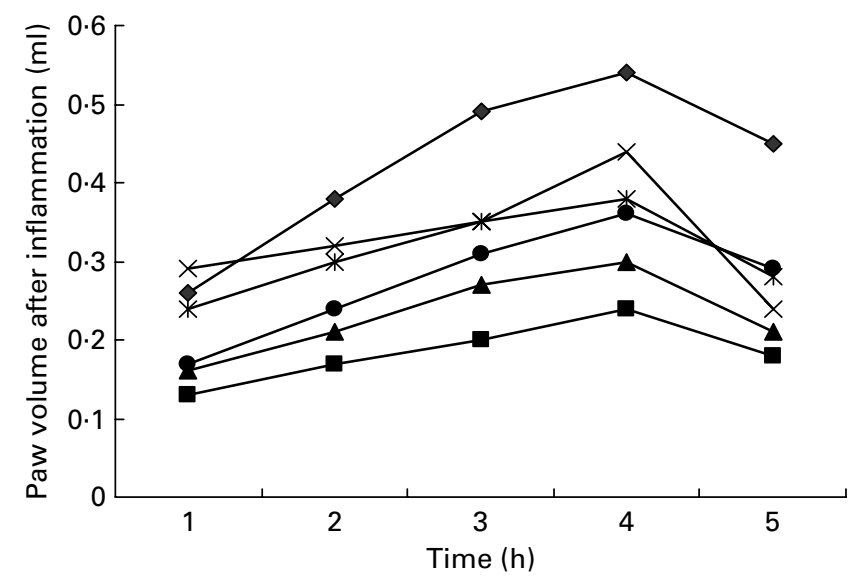

Fig. 2. Effects of three doses of $\alpha$-lipoic acid (ALA) and one dose of indomethacin (IND) or diclofenac (DIC) on carrageenan (CAR)-injected rats, with time-dependent increase in the rat's paw volume after CAR injection. Three doses of ALA (50, 100 and $200 \mathrm{mg} / \mathrm{kg})$ and one dose of IND $(25 \mathrm{mg} / \mathrm{kg})$ or DIC $(25 \mathrm{mg} / \mathrm{kg})$ were administered to rats by oral administration. The paw volumes of the animals were calculated plethysmometrically, and $0.1 \mathrm{ml}$ of $1 \%$ CAR was injected into the hind paw of each animal $1 \mathrm{~h}$ after oral drug administration. $-\bullet-$, CAR; $-\boldsymbol{-}-$, CAR + IND; $-\boldsymbol{\Delta}-$, CAR + DIC; $-\times-$, $\mathrm{CAR}+\mathrm{ALA}(50 \mathrm{mg} / \mathrm{kg}) ; \rightarrow$ - CAR + ALA $(100 \mathrm{mg} / \mathrm{kg}) ;-\bullet-, \mathrm{CAR}+\mathrm{ALA}$ (200 mg/kg).

Glutathione peroxidase activity. GPx activity was determined according to a previously reported method ${ }^{(31)}$. The absorbance at $340 \mathrm{~nm}$ was recorded for $5 \mathrm{~min}$. The activity was determined by measuring the amount of oxidised NADPH as $\mu \mathrm{mol} / \mathrm{min}$ per $\mathrm{mg}$ tissue.

Glutathione reductase activity. GR activity was determined spectrophotometrically by measuring the rate of $\mathrm{NADPH}$ oxidation at $340 \mathrm{~nm}^{(32)}$. Results are expressed as the amount of enzymes required to catalyse the oxidation of $1 \mu \mathrm{mol}$ of $\mathrm{NADPH} / \mathrm{min}$ per mg of tissue.

Catalase activity. Decomposition of $\mathrm{H}_{2} \mathrm{O}_{2}$ in the presence of a CAT was measured at $240 \mathrm{~nm}^{(33)}$. CAT activity was defined as the amount of enzymes required to decompose $1 \mathrm{nmol}$ of $\mathrm{H}_{2} \mathrm{O}_{2} / \mathrm{min}$, at $25^{\circ} \mathrm{C}$ and $\mathrm{pH} 7 \cdot 8$. Results are expressed as $\mathrm{mmol} / \mathrm{min}$ per $\mathrm{mg}$ of tissue.

Superoxide dismutase activity. As outlined by Sun et al. ${ }^{(34)}$, SOD estimation was based on the generation of superoxide radicals produced by xanthine and xanthine oxidase, which reacts with nitro blue tetrazolium to form formazan dye. SOD activity was then measured at $560 \mathrm{~nm}$ by the degree of inhibition of this reaction and is expressed as $\mathrm{mmol} / \mathrm{min}$ per $\mathrm{mg}$ of tissue.

Inducible nitric oxide synthase activity. NOS activity was measured spectrophotometrically using the oxidation of oxyhaemoglobin to methaemoglobin by $\mathrm{NO}$ as described previously ${ }^{(35,36)}$. The absorption difference between 401 and $421 \mathrm{~nm}$ was continuously monitored with a dual wavelength recording spectrophotometer (Thermo Spectronic-HEגIOS $\beta$, Cambridge, UK) at $37^{\circ} \mathrm{C}$. For total NOS assay, the incubation medium contained $1.6 \mu \mathrm{m}$-oxyhaemoglobin, $200 \mu \mathrm{m}-\mathrm{CaCl}_{2}, 1 \mathrm{~mm}-\mathrm{MgCl}_{2}, 100 \mu \mathrm{m}-\mathrm{L}$-arginine,
$100 \mu \mathrm{m}-\mathrm{NADPH}, \quad 40 \mathrm{~mm}$-potassium phosphate (pH 7.2), $1 \mathrm{~mm}-\mathrm{NG}$-nitro-L-arginine and $10 \%(\mathrm{v} / \mathrm{v})$ tissue extract with $50 \mathrm{~mm}$-L-valine to inhibit arginase. For the cNOS (constitutive) assay, $1 \mathrm{~mm}$-glycol diethyl ether diamine tetraacetic acid was added to the above-mentioned incubation medium without NG-nitro-L-arginine. Oxyhaemoglobin oxidation was confirmed as being caused by NO synthesis. iNOS activity was calculated by subtracting the cNOS activity from the total NOS activity.

Myeloperoxidase activity. MPx activity was measured according to the modified method of Bradley et al. ${ }^{(37)}$. The homogenised samples were frozen and thawed three times, and centrifuged at $1500 \mathrm{~g}$ for $10 \mathrm{~min}$ at $4^{\circ} \mathrm{C}$. MPx activity in the supernatant was determined by adding $100 \mathrm{ml}$ of the supernatant to $1.9 \mathrm{ml}$ of a $10 \mathrm{mmol} / 1$ phosphate buffer ( $\mathrm{pH} 6.0)$ and $1 \mathrm{ml}$ of $1.5 \mathrm{mmol} / \mathrm{l}$ o-dianisidine dihydrochloride containing $0.0005 \%$ (w/v) $\mathrm{H}_{2} \mathrm{O}_{2}$. The changes in absorbance at $450 \mathrm{~nm}$ of each sample were recorded on a UV-visible spectrophotometer (Fig. 3). MPx activity in tissues was expressed as $\mu \mathrm{mol} / \mathrm{min}$ per mg tissue.

Total GSH determination. The amount of GSH in the paw oedema was measured according to the method of Sedlak \& Lindsay ${ }^{(38)}$. The paw oedema was collected by scraping, then it was weighed and homogenised in $2 \mathrm{ml}$ of a $50 \mathrm{~mm}$-Tris-HCl buffer containing $20 \mathrm{~mm}$ EDTA and $0.2 \mathrm{M}$-sucrose at a pH of 7.5. The homogenate was centrifuged. After centrifugation at $4200 \mathrm{rpm}$ for $40 \mathrm{~min}$ at $4^{\circ} \mathrm{C}$, the supernatant was used to determine GSH using 5,5'-dithiobis(2-nitrobenzoic acid). Absorbance was measured at $412 \mathrm{~nm}$ using a spectrophotometer. The results of the GSH level in the paws were expressed as $\mathrm{nmol} / \mathrm{mg}$ tissue.

\section{Determination of lipid peroxidation or malonaldehyde formation}

The levels of LPO were determined by estimating malonaldehyde using the thiobarbituric acid test ${ }^{(39)}$. Briefly, the rat stomachs were promptly excised and rinsed with cold saline. To minimise the possibility of interference of $\mathrm{Hb}$ with free radicals, any blood adhering to the mucosa was carefully removed. The paw tissues were scraped, weighed and homogenised in $10 \mathrm{ml}$ of $100 \mathrm{~g} / 1 \mathrm{KCl}$. The homogenate $(0.5 \mathrm{ml})$ was added with a solution containing $0.2 \mathrm{ml}$ of $80 \mathrm{~g} / 1$ sodium laurylsulphate, $1.5 \mathrm{ml}$ of $200 \mathrm{~g} / 1$ acetic acid, $1.5 \mathrm{ml}$ of $8 \mathrm{~g} / \mathrm{l} \mathrm{2}$-thiobarbiturate and $0.3 \mathrm{ml}$ distilled water. The mixture was incubated at $98^{\circ} \mathrm{C}$ for $1 \mathrm{~h}$. Upon cooling, $5 \mathrm{ml}$ of $n$-butanol-pyridine (15:1) was added. The mixture was vortexed for $1 \mathrm{~min}$ and centrifuged for $30 \mathrm{~min}$ at $4000 \mathrm{rpm}$. The supernatant was measured at $532 \mathrm{~nm}$. The standard curve was obtained using 1,1,3,3,-tetramethoxypropane. The recovery was over $90 \%$. All the samples were measured in duplicate. The results were expressed as nmol malonaldehyde/g of wet tissue. 


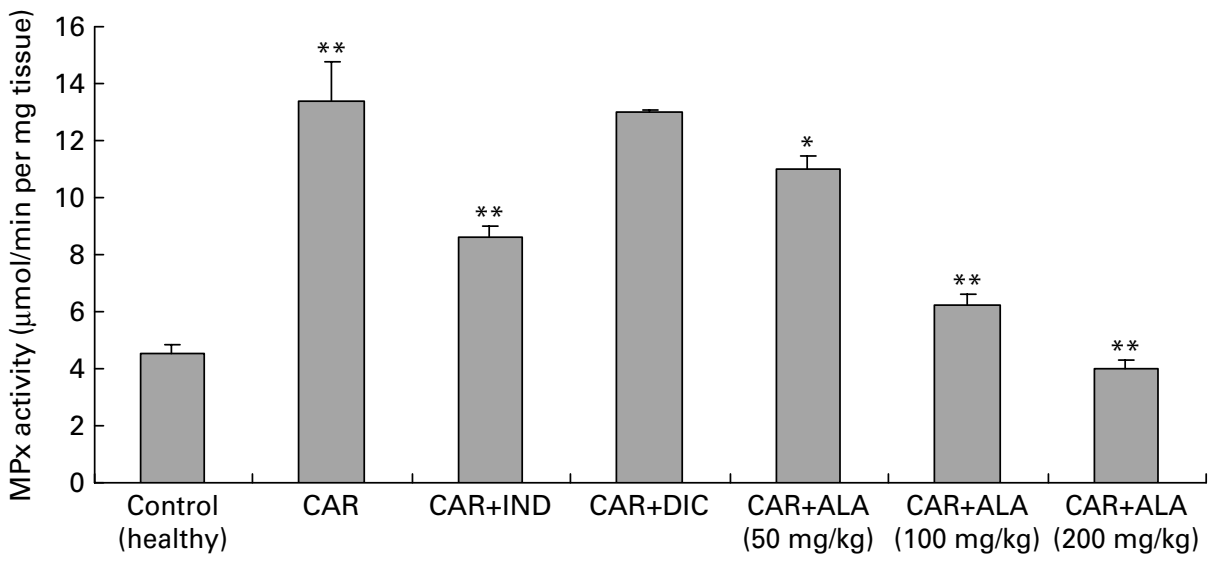

Fig. 3. Effects of $\alpha$-lipoic acid (ALA), indomethacin (IND) and diclofenac (DIC) on changes in the activity of myeloperoxidase (MPx) enzyme in carrageenan (CAR)-injected rat paws (fifth hour). Three doses of ALA (50, 100 and $200 \mathrm{mg} / \mathrm{kg}$ ) and one dose of IND (25 mg/kg) or DIC (25 mg/kg) were administered to rats by oral administration. The paw volumes of the animals were calculated plethysmometrically, and $0.1 \mathrm{ml}$ of $1 \%$ CAR was injected into the hind paw of each animal $1 \mathrm{~h}$ after oral drug administration. (The same experiment has been performed three times, and then data determined are expressed as means with standard errors of three parallel measurements. Three doses of ALA-treated group and one dose of IND- and DIC-treated groups were compared with the CAR group. The CAR group was compared with the healthy group.) Mean values were significantly different: ${ }^{\star} P<0.05,{ }^{\star \star} P<0.01$.

\section{Cotton pellet-induced granuloma test in rats}

In this series of experiments, the effect of ALA on the proliferative phase of inflammation was investigated using the cotton pellet test ${ }^{(8)}$. Animals were divided into six groups each consisting of six rats (Table 2). Three groups of animals received ALA at doses of 50, 100 and $200 \mathrm{mg} / \mathrm{kg}$ body weight (wt) with the aids of gavages, while the other groups of animals received DIC at a dose of $25 \mathrm{mg} / \mathrm{kg}$ body wt and IND at a dose of $25 \mathrm{mg} / \mathrm{kg}$ body wt orally, and the control group received an equal volume of distilled water. Thirty minutes after administration of the drugs, the animals were anaesthetised using $25 \mathrm{mg} / \mathrm{kg}$ body wt sodium thiopental. Under sterilised conditions, cotton pellets of 7 (SEM 1) mg were implanted subcutaneously in the interscapular area. ALA, DIC and IND were administered once a day for $7 \mathrm{~d}$ at the doses indicated earlier. On the eighth day, the animals were killed via high-dose anaesthesia, and the cotton pellets with the granuloma tissue about them were removed. The wet weights of these pellets were measured, and the anti-proliferative effects of ALA, DIC and IND were determined by comparison with the control group.

\section{Total antioxidant activity assays}

The total antioxidant activities of ALA were determined by the thiocyanate method ${ }^{(3,40)}$ and compared with known antioxidants, trolox and ascorbic acid. Briefly, each sample $(1 \mathrm{mg})$ in $1 \mathrm{ml}$ distilled water was mixed with $5 \mathrm{ml}$ linoleic acid emulsion $(0.02 \mathrm{M}, \mathrm{pH} 7.0)$ and $5 \mathrm{ml}$ of the phosphate buffer $(0 \cdot 2 \mathrm{~m}, \mathrm{pH} 7 \cdot 0)$. The linoleic acid emulsion was prepared by mixing $0.5608 \mathrm{~g}$ of linoleic acid

Table 2. Effects of $\alpha$-lipoic acid (ALA), indomethacin (IND) and diclofenac (DIC) on cotton pellet-induced granuloma test in rats†

(Mean values with their standard errors)

\begin{tabular}{|c|c|c|c|c|c|c|c|}
\hline \multirow[b]{2}{*}{ Treatment } & \multirow[b]{2}{*}{$n$} & \multirow{2}{*}{$\begin{array}{c}\text { Dose } \\
\text { (mg/kg body wt) }\end{array}$} & \multicolumn{2}{|c|}{$\begin{array}{l}\text { Cotton pellet } \\
\text { weight }(\mathrm{mg})\end{array}$} & \multicolumn{2}{|c|}{$\begin{array}{l}\text { Granuloma } \\
\text { (wt/mg) }\end{array}$} & \multirow{2}{*}{$\begin{array}{c}\text { Anti-proliferative } \\
\text { effect }(\%) \ddagger\end{array}$} \\
\hline & & & Mean & SEM & Mean & SEM & \\
\hline ALA & 6 & 50 & 7 & 1 & $146^{\star \star}$ & 3.8 & $67 \cdot 7$ \\
\hline ALA & 6 & 100 & 7 & 1 & $141^{\star *}$ & 3.8 & 68.9 \\
\hline ALA & 6 & 200 & 7 & 1 & $133^{\star *}$ & $4 \cdot 1$ & $70 \cdot 6$ \\
\hline DIC & 6 & 25 & 7 & 1 & $108^{\star *}$ & 4.9 & $76 \cdot 1$ \\
\hline IND & 6 & 25 & 7 & 1 & $73^{\star *}$ & $5 \cdot 71$ & 83.8 \\
\hline Control & 6 & - & 7 & 1 & 452 & $9 \cdot 6$ & - \\
\hline
\end{tabular}

$n$, Number of animals.

Mean values were significantly different when compared with that of the control group: ${ }^{\star \star} P<0.01$

† Three doses of ALA $(50,100$ and $200 \mathrm{mg} / \mathrm{kg})$ and one dose of IND $(25 \mathrm{mg} / \mathrm{kg})$ or DIC $(25 \mathrm{mg} / \mathrm{kg})$ were administered to rats by oral administration. At $30 \mathrm{~min}$ after administration of the drugs, cotton pellets were implanted subcutaneously in the interscapular area under anaesthesia. ALA, DIC and IND were administered once a day for $7 \mathrm{~d}$. On the eighth day, the cotton pellets with the granuloma tissue about them were removed. Three doses of the ALA-treated group, and one dose of the IND- or DIC-treated groups were compared with the control group.

$\ddagger$ Inhibition in granuloma weights in relation to the control (untreated) group. 
with $0.5608 \mathrm{~g}$ of Tween-20 as an emulsifier and $100 \mathrm{ml}$ of the phosphate buffer, and then the mixture was homogenised. The reaction mixture was incubated at $37^{\circ} \mathrm{C}$. Aliquots of $0.1 \mathrm{ml}$ were taken at different intervals during incubation. The degree of oxidation was measured according to the thiocyanate method by sequentially adding $4.7 \mathrm{ml}$ ethanol (75\%), $0.1 \mathrm{ml}$ ammonium thiocyanate (30\%), $0.1 \mathrm{ml}$ sample solution and $0.1 \mathrm{ml}$ ferrous chloride $(0.02 \mathrm{M}$, in $3.5 \% \mathrm{HCl})$. The mixture was allowed to stand for 3 min and then the peroxide value was determined by reading the absorbance at $500 \mathrm{~nm}$ using the UV-visible spectrophotometer (Thermo Spectronic-HEגIOS $\beta$ ). A control was performed with linoleic acid but without the extracts. Inhibition \% was calculated using the following formula:

$$
\text { Inhibition } \%=(1-(\text { absorbance of sample at } 500 \mathrm{~nm} /
$$

$$
\text { absorbance of control at } 500 \mathrm{~nm})) \times 100 \text {. }
$$

Trolox and ascorbic acid solutions prepared in the conditions mentioned earlier were used as positive controls.

\section{Statistical analyses}

Data of enzyme activities and inflammation were subjected to one-way ANOVA, with the presence of negative and positive controls, by using SPSS 11.0 software (SPSS, Inc., Chicago, IL, USA). Differences among the groups were attained using the least significant difference option, and significance was declared at $P<0.05,0.01$ and 0.005.

\section{Results}

\section{Carrageenan-induced paw oedema}

Intraplantar injection of CAR in rats led to a quadratic and time-dependent increase in paw volume (Fig. 2).
The increase in paw volume was observed at $1 \mathrm{~h}$ and was maximal at $4 \mathrm{~h}$ after the administration. However, CAR-induced paw oedema was reduced in a dose-dependent manner by treatment with ALA at 1, 2, 3, 4 and $5 \mathrm{~h}$ after an injection of CAR (Fig. 2). At doses of 100 and $200 \mathrm{mg} / \mathrm{kg}$, ALA significantly $(P<0.05$ and 0.01$)$ reduced CAR-induced paw oedema by 29.6 and $40.7 \%$, respectively, at the fourth hour (Table 1). At doses of $25 \mathrm{mg} / \mathrm{kg}$, treating DIC and IND also significantly reduced the oedema by 44.4 and $55.5 \%$, respectively. The paw volume increased by $0.54 \mathrm{ml}$ in the control group relative to the baseline values, while increases of $0.44,0.38,0.32$, 0.24 and $0.30 \mathrm{ml}$ were observed in the groups administered with 50,100 and $200 \mathrm{mg} / \mathrm{kg}$ of ALA, IND and DIC, respectively. The present results show that IND, DIC, and 100 and $200 \mathrm{mg} / \mathrm{kg}$ of ALA (Fig. 2) had significant anti-inflammatory effects against the paw oedema caused by CAR. The anti-inflammatory effect of ALA was also weaker than that of DIC and IND, which inhibit PG synthesis by cyclo-oxygenase.

\section{Comparison of enzymatic activities and lipid peroxidation or GSH levels in rat paw tissues}

In order to explore the effects of antioxidant defences on the inflammation process in all paw tissues, the activities of antioxidant enzymes (GST, GPx, GR SOD and CAT) and the amounts of GSH and LPO were evaluated. The results are presented in Tables 3 and 4 with Figs 4 and 5 . Table 3 shows that the activities of GPx, GR and SOD for CAR-injected groups were lower, and GST and CAT activities were higher than those for the healthy rat group. However, compared with GST, GPx and SOD levels in ALA-administered paw tissues, the opposite results were found for the activities of these enzymes in CAR-injected tissues. In contrast to CAR-injected paws,

Table 3. Effects of $\alpha$-lipoic acid (ALA), indomethacin (IND) and diclofenac (DIC) on changes in the activities of some glutathione metabolism enzymes ((glutathione S-transferase (GST), glutathione peroxidase (GPx) and glutathione reductase (GR)) in CAR-injected paws (fifth hour) of rats $\dagger$

\begin{tabular}{|c|c|c|c|c|c|c|c|}
\hline \multirow[b]{2}{*}{ Treatmentł } & \multirow{2}{*}{$\begin{array}{c}\text { Dose } \\
\text { (mg/kg body wt) }\end{array}$} & \multicolumn{2}{|c|}{$\begin{array}{l}\text { GST activity } \\
\text { (nmol/min per } \\
\mathrm{mg} \text { tissue) }\end{array}$} & \multicolumn{2}{|c|}{$\begin{array}{l}\text { GPx activity } \\
\text { ( } \mu \mathrm{mol} / \mathrm{min} \text { per } \\
\mathrm{mg} \text { tissue })\end{array}$} & \multicolumn{2}{|c|}{$\begin{array}{c}\text { GR activity } \\
(\mu \mathrm{mol} / \mathrm{min} \text { per } \\
\mathrm{mg} \text { tissue })\end{array}$} \\
\hline & & Mean & SEM & Mean & SEM & Mean & SEM \\
\hline $\mathrm{CAR}+\mathrm{ALA}$ & 50 & $15 \cdot 12$ & 0.35 & 21.49 & 0.07 & 19.07 & 0.26 \\
\hline $\mathrm{CAR}+\mathrm{ALA}$ & 100 & $14.53^{\star}$ & 0.56 & $22 \cdot 65^{\star}$ & 0.49 & $18 \cdot 61$ & 0.31 \\
\hline $\mathrm{CAR}+\mathrm{ALA}$ & 200 & $12 \cdot 90^{\star \star}$ & 0.19 & $23 \cdot 67^{\star \star}$ & 0.45 & 18.40 & 0.15 \\
\hline CAR + DIC & 25 & $14 \cdot 47^{\star}$ & 0.08 & $22 \cdot 84^{\star}$ & 0.19 & $20 \cdot 17^{*}$ & 0.37 \\
\hline CAR + IND & 25 & $17 \cdot 74^{\star \star}$ & 0.43 & $23 \cdot 22^{\star \star}$ & 0.47 & $20 \cdot 79^{\star}$ & 0.13 \\
\hline CAR & - & $15 \cdot 74^{\star *}$ & 0.51 & 21.44 & 0.12 & $18 \cdot 8^{\star *}$ & 0.05 \\
\hline Control (healthy) & - & 13.90 & 0.11 & 22.33 & 0.63 & $29 \cdot 31$ & 0.26 \\
\hline
\end{tabular}

(Mean values with their standard errors of three parallel measurements)

$n$, Number of animals.

Mean values were significantly different when compared to that of control group: ${ }^{\star} P<0.05,{ }^{\star \star} P<0.01$.

† Three doses of ALA (50, 100 and $200 \mathrm{mg} / \mathrm{kg}$ ), and one dose of IND (25 mg/kg) or DIC (25 mg/kg) were administered to rats by oral administration. Three doses of the ALA-treated group, and one dose of the IND- or DIC-treated groups were compared with the CAR group. The CAR group was compared with the healthy group. The paw volumes of the animals were calculated plethysmometrically, and $0.1 \mathrm{ml}$ of $1 \%$ CAR was injected into the hind paw of each animal $1 \mathrm{~h}$ after oral drug administration.

¥ The same experiment was performed three times and then data determined are expressed as means with their standard errors of three parallel measurements. 
Table 4. Effects of $\alpha$-lipoic acid (ALA), indomethacin (IND) and diclofenac (DIC) on changes in the activity of catalase (CAT) and superoxide dismutase (SOD) enzymes in CAR-injected paws (fifth hour) of rats $†$ (Mean values with their standard errors of three parallel measurements)

\begin{tabular}{|c|c|c|c|c|c|}
\hline \multirow[b]{2}{*}{ Treatmentł } & \multirow{2}{*}{$\begin{array}{c}\text { Dose } \\
\text { (mg/kg body wt) }\end{array}$} & \multicolumn{2}{|c|}{$\begin{array}{l}\text { CAT activity } \\
\text { (mmol/min per } \\
\mathrm{mg} \text { tissue) }\end{array}$} & \multicolumn{2}{|c|}{$\begin{array}{c}\text { SOD activity } \\
\text { (mmol/min per } \\
\text { mg tissue) }\end{array}$} \\
\hline & & Mean & SEM & Mean & SEM \\
\hline CAR + ALA & 50 & $133 \cdot 0^{\star *}$ & $2 \cdot 9$ & $125 \cdot 4^{*}$ & 0.33 \\
\hline $\mathrm{CAR}+\mathrm{ALA}$ & 100 & $166 \cdot 0^{\star *}$ & 2.9 & $129 \cdot 1^{*}$ & 0.34 \\
\hline $\mathrm{CAR}+\mathrm{ALA}$ & 200 & $194.0^{* *}$ & $3 \cdot 2$ & $136 \cdot 2^{\star \star}$ & 0.75 \\
\hline $\mathrm{CAR}+\mathrm{DIC}$ & 25 & $88 \cdot 4^{\star *}$ & 1.2 & $128 \cdot 6^{\star}$ & 0.61 \\
\hline$C A R+I N D$ & 25 & $91.5^{\star *}$ & 1.5 & $119 \cdot 8$ & 0.68 \\
\hline CAR & - & $117 \cdot 6^{\star \star}$ & 1.5 & $121 \cdot 1^{\star \star}$ & 1.07 \\
\hline Control (healthy) & - & 91.0 & $1 \cdot 1$ & $132 \cdot 3$ & 0.72 \\
\hline
\end{tabular}

$n$, Number of animals.

Mean values were significantly different when compared to that of the control group: ${ }^{*} P<0.05,{ }^{\star *} P<0.01$

† Three doses of ALA (50, 100 and $200 \mathrm{mg} / \mathrm{kg})$, and one dose of IND $(25 \mathrm{mg} / \mathrm{kg})$ or DIC $(25 \mathrm{mg} / \mathrm{kg})$ were administered to rats by oral administration. Three doses of the ALA-treated group and one dose of the IND- or DIC-treated groups were compared with the CAR group. The CAR group was compared with the healthy group. The paw volumes of the animals were calculated plethysmometrically, and $0.1 \mathrm{ml}$ of $1 \%$ CAR was injected into the hind paw of each animal $1 \mathrm{~h}$ after oral drug administration.

$\ddagger$ The same experiment was performed three times.

DIC and IND increased the activities of GPx and GR $(P<0.05)$ and decreased CAT activity $(P<0.05)$. Table 3 shows that the activity of GST was decreased by the administration of 50 and $100 \mathrm{mg}$ ALA per $\mathrm{kg}(P<0.05)$, while the activity of GR was reduced during CAR oedema and this reduction was not affected by all the doses of ALA $(P>0.05)$. Similarly, DIC decreased GST activity but increased GR activity $(P<0.05)$. However, IND increased both the activity of GST elevated by CAR further and the activity of GR alleviated by CAR. The activity of GPx was 22.33 in healthy paws. This score was decreased by CAR to $21.44(P>0.05)$, but it was increased by 50 and $100 \mathrm{mg} / \mathrm{kg}$ doses of ALA $(P<0.05$ and $P<0.01)$, DIC $(P<0.05)$ and IND $(P>0.01)$. However, compared with the activities of the CAT and SOD enzymes in ALA-, INDand DIC-administered paw tissues, different results were found. The injected CAR increased CAT activity, while decreased SOD activity in paw tissues. In contrast to CAR-injected paws, all the doses of ALA and DIC increased SOD activity $(P<0.05)$, while DIC and IND decreased CAT activity $(P<0.05)$. On the other hand, CAT activity was elevated significantly $(P<0 \cdot 01)$ by all the doses of ALA further (Table 4). Likewise, both IND with DIC and all the doses of ALA had an increasing effect $(P<0.05)$ on the level of GSH alleviated by CAR (Fig. 4), and in contrast to CAR-injected paws (Fig. 5), all the doses of ALA and DIC decreased the amount of LPO $(P<0 \cdot 01)$.

In the present study, changes in MPx activity of paw tissues were widely used as an index of neutrophil infiltration in gastric and inflammatory tissue damage. MPx activity was determined by using an appropriate method. It is observed from Fig. 3 that the administration of CAR significantly $(P<0 \cdot 01)$ increased the MPx activity. In contrast to CAR injection, the administration of the $50(P<0 \cdot 05), 100$ and $200(P<0.01) \mathrm{mg} / \mathrm{kg}$ doses of ALA and $25 \mathrm{mg} / \mathrm{kg}$ dose of IND reduced the level of MPx; however, DIC did not indicate any effect. Separately, iNOS activity in the rat paw tissues was also given in the Table 5. The intraplantar injection of CAR increased significantly iNOS activities $(P<0.01)$ in paw homogenates at the fifth hour. The activity of iNOS was $0 \cdot 14$ in healthy paws. This score was elevated by CAR to $0.36(P<0.05)$, but it was alleviated by CAR + DIC, CAR + IND and CAR + ALA (50, 100 and $200 \mathrm{mg} / \mathrm{kg}$ doses) to $0 \cdot 18,0 \cdot 22,0 \cdot 17,0 \cdot 13$ and $0 \cdot 11$, respectively $(P<0 \cdot 01)$.

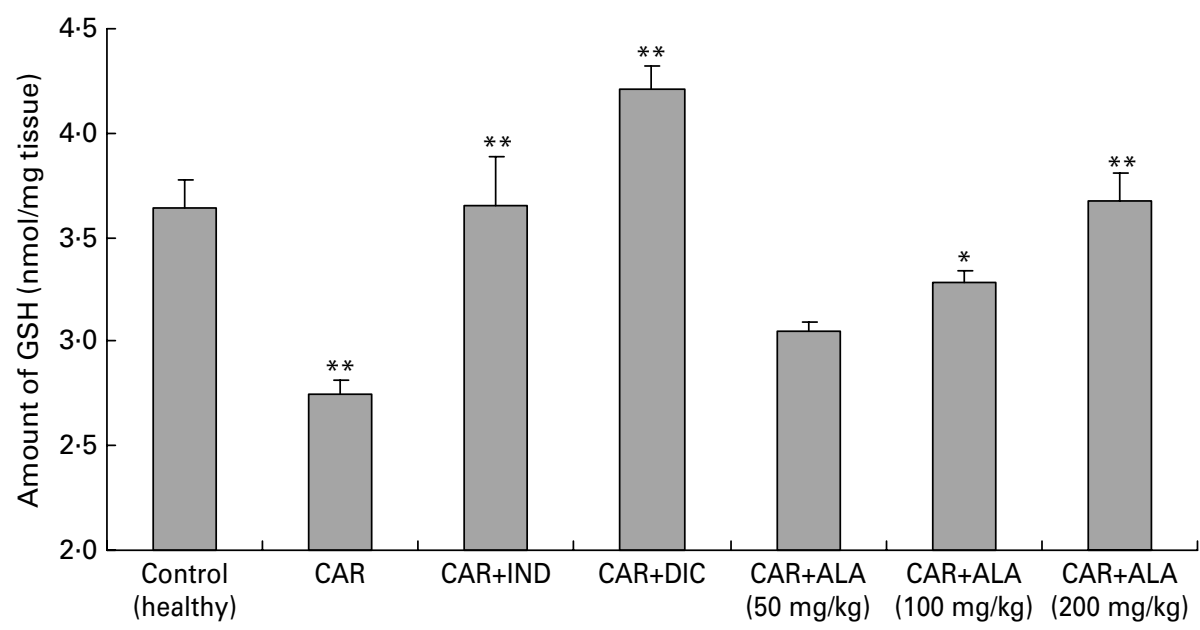

Fig. 4. Effects of $\alpha$-lipoic acid (ALA), indomethacin (IND) and diclofenac (DIC) on changes in level the of GSH in carrageenan (CAR)-injected rat paws (fifth hour). Three doses of ALA $(50,100$ and $200 \mathrm{mg} / \mathrm{kg})$ and one dose of IND $(25 \mathrm{mg} / \mathrm{kg})$ or DIC $(25 \mathrm{mg} / \mathrm{kg})$ were administered to rats by oral administration. The paw volumes of the animals were calculated plethysmometrically, and $0.1 \mathrm{ml}$ of $1 \%$ CAR was injected into the hind paw of each animal $1 \mathrm{~h}$ after oral drug administration. (The same experiment has been performed three times and then data determined are expressed as means with standard errors of three parallel measurements. Three doses of the ALA-treated group, and one dose of the IND- and DIC-treated groups were compared with the CAR group. The CAR group was compared with the healthy group.) Mean values were significantly different: ${ }^{\star} P<0.05,{ }^{\star \star} P<0.01$. 


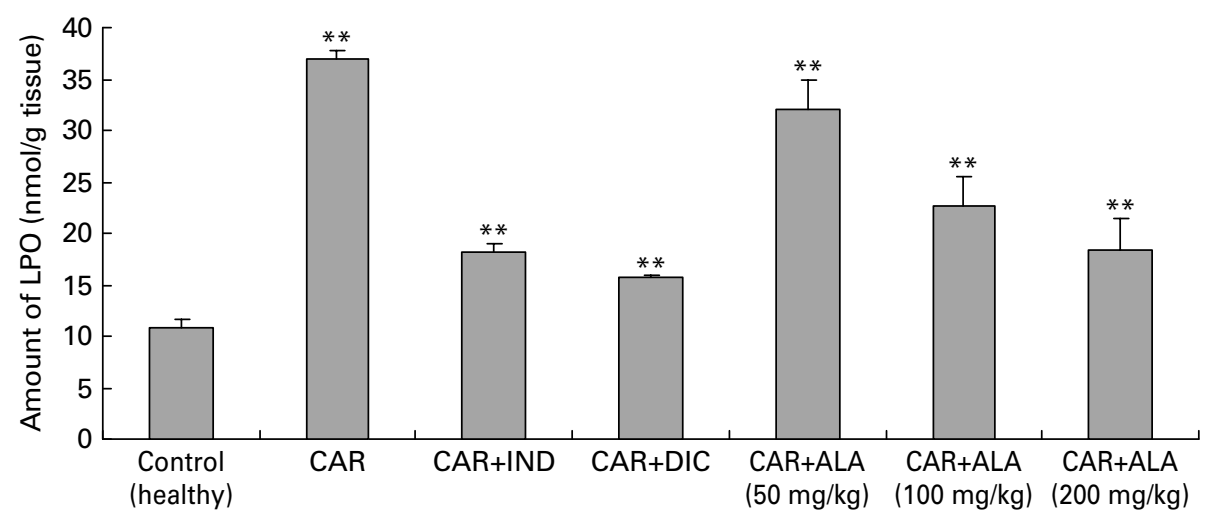

Fig. 5. Effects of $\alpha$-lipoic acid (ALA), indomethacin (IND) and diclofenac (DIC) on changes in the amount of lipid peroxidation (LPO) in carrageenan (CAR)-injected rat paws (fifth hour). Three doses of ALA $(50,100$ and $200 \mathrm{mg} / \mathrm{kg})$ and one dose of IND $(25 \mathrm{mg} / \mathrm{kg})$ or DIC $(25 \mathrm{mg} / \mathrm{kg})$ were administered to rats by oral administration. The paw volumes of the animals were calculated plethysmometrically, and $0.1 \mathrm{ml}$ of $1 \%$ CAR was injected into the hind paw of each animal $1 \mathrm{~h}$ after oral drug administration. (The same experiment has been performed three times and then the data determined are expressed as means with standard errors of three parallel measurements. Three doses of the ALA-treated group, and one dose of the IND- and DIC-treated groups were compared with the CAR group. The CAR group was compared with the healthy group.) Mean values were significantly different: ${ }^{\star *} P<0.01$.

\section{Cotton pellet-induced granuloma test}

As shown in Table 2, the mean weight of the cotton pellets in the ALA $(50,100$ and $200 \mathrm{mg} / \mathrm{kg}$ body wt) groups was 146 (SEM 3.8), 141 (SEM 3.8) and 136 (SEM 4.1) $\mathrm{mg}$, respectively, while it was 108 (SEM 4.9) and 73 (SEM 5.71) $\mathrm{mg}$ in the DIC $(25 \mathrm{mg} / \mathrm{kg}$ body wt) and IND $(25 \mathrm{mg} / \mathrm{kg}$ body $\mathrm{wt})$, respectively. According to these results, the anti-proliferative effect of ALA (50, 100 and $200 \mathrm{mg} / \mathrm{kg}$ body wt) groups was shown to be $67 \cdot 7,68.9$ and $70.6 \%$, respectively, and of DIC was $76.1 \%$ and of IND was an $83.8 \%$ response. The present results show that ALA in all the doses also has significant $(P<0 \cdot 01)$ anti-inflammatory effects on the chronic inflammation process.

Table 5. Effects of $\alpha$-lipoic acid (ALA), indomethacin (IND) and diclofenac (DIC) on changes in the activity of inducible nitric oxide synthase (iNOS) enzyme in CAR-injected paws (fifth hour) of rats $†$

(Mean values with their standard errors of three parallel measurements)

\begin{tabular}{lcll}
\hline & & \multicolumn{2}{c}{$\begin{array}{c}\text { iNOS (nmol/min per } \\
\text { mg tissue) }\end{array}$} \\
\cline { 3 - 4 } Treatment $\ddagger$ & $\begin{array}{c}\text { Dose } \\
\text { (mg/kg body wt) }\end{array}$ & Mean & SEM \\
\hline CAR + ALA & 50 & $0.17^{\star \star}$ & 0.02 \\
CAR + ALA & 100 & $0.13^{\star *}$ & 0.05 \\
CAR + ALA & 200 & $0.11^{\star *}$ & 0.03 \\
CAR + DIC & 25 & $0 \cdot 18^{\star *}$ & 0.03 \\
CAR + IND & 25 & $0.22^{\star *}$ & 0.01 \\
CAR & - & $0.36^{\star *}$ & 0.06 \\
Control (healthy) & - & 0.14 & 0.03 \\
\hline
\end{tabular}

$n$, Number of animals.

Mean values were significantly different when compared to that of control group: ${ }^{\star \star} P<0.01$.

† Three doses of ALA (50, 100 and $200 \mathrm{mg} / \mathrm{kg})$, and one dose of IND ( $25 \mathrm{mg} / \mathrm{kg}$ ) or DIC $(25 \mathrm{mg} / \mathrm{kg})$ were administered to rats by oral administration. Three doses of the ALA-treated group, and one dose of the DIC- and IND-treated groups were compared with the CAR group. The CAR group was compared with the healthy group. The paw volumes of the animals were calculated plethysmometrically, and $0.1 \mathrm{ml}$ of $1 \%$ CAR was injected into the hind paw of each animal $1 \mathrm{~h}$ after oral drug administration.

‡ The same experiment was performed three times.

\section{In vitro antioxidant activity of $\alpha$-lipoic acid}

ROS had negative effects on the pathogenesis of inflammation and gastric ulcer. Because of this, antioxidants may be effective on the pathogenesis of these diseases. Therefore, in the present study, the in vitro antioxidant action of ALA was also determined using thiocyanate methods and compared to the positive controls, trolox and ascorbic acid (Table 6). ALA in $5 \mathrm{mg}$ acted as a powerful antioxidant by inhibiting the peroxidation of linoleic acid with $79.1 \%$. In particular, in 1 and $2.5 \mathrm{mg}$, ALA showed weak antioxidant potential.

\section{Discussion}

Inflammatory processes are the physiological response of the organism to different stimulants such as trauma, infections or immunological mechanisms. The arachidonic acid cascade is highly activated during inflammation, resulting in the formation of eicosanoids, and it is mediated by cyclo-oxygenase and 5-lipoxygenase enzymes. These complex inflammatory reactions involve the release of a wide variety of inflammatory mediators, i.e. PG, thromboxanes and leukotrienes. Although drugs with a central mechanism of anti-pyretic and anti-inflammatory actions are known to down-regulate fever and inflammation, the role of the antioxidant mechanism pathway in mediating the action of such agents is still unknown.

In the present study, the anti-inflammatory effects of the ALA, a highly effective antioxidant agent, were investigated. The effect of ALA on the acute phase of inflammation was observed in the CAR-induced paw oedema test, and its anti-inflammatory potency was compared to DIC and IND. In our experiment, the mean paw volume of the control group reached its peak at the fourth hour. The mean paw volume in the groups receiving CAR, ALA, DIC and IND started to decrease at the fourth hour. At doses of 50,100 and $200 \mathrm{mg} / \mathrm{kg}$, ALA significantly 
Table 6. Antioxidant activity of three doses of $\alpha$-lipoic acid (ALA) and one dose of positive controls (Trolox and ascorbic acid) on linoleic acid oxidation, in vitro

(Mean values with their standard errors)

\begin{tabular}{lllc}
\hline & \multicolumn{3}{c}{ Total antioxidant activity } \\
\cline { 2 - 3 } & \multicolumn{2}{c}{$\begin{array}{c}\text { Absorbance } \\
\text { (forty-fourth hour, } \\
\text { Samples }\end{array}$} & \multicolumn{2}{c}{$500 \mathrm{~nm}$ ) } & \\
\cline { 2 - 3 } & Mean & SEM & Inhibition (\%) \\
ALA (1 mg) & $0.527^{*}$ & 0.58 & 34.9 \\
ALA (2.5 mg) & $0.333^{*}$ & 0.25 & 58.9 \\
ALA (5 mg) & $0.169^{* *}$ & 0.31 & 79.1 \\
Trolox (1 mg) & $0.057^{* *}$ & 0.01 & 93.0 \\
Ascorbic acid (1 mg) & 0.694 & 0.02 & 14.3 \\
Control & 0.810 & 0.04 & - \\
\hline
\end{tabular}

Mean values were significantly different when compared to that of the control group: ${ }^{*} P<0.05,{ }^{* \star} P<0.01$

$(P<0 \cdot 01)$ reduced CAR-induced paw oedema by $18 \cdot 5,29 \cdot 6$ and $40.7 \%$, respectively, at the fourth hour (Table 1 ). DIC and IND, which significantly reduced the increase in paw volume by 44.4 and $55.5 \%$, respectively, showed a greater effect in this model of inflammation.

CAR injection into the rat paw provokes a local, acute inflammatory reaction which is a suitable method for evaluating anti-inflammatory agents ${ }^{(2-5,8)}$. It appears that the delayed onset of CAR-induced oedema has been linked to inflammation mediators such as NO, PG, cytokines and free radicals, such as $\mathrm{H}_{2} \mathrm{O}_{2}$, superoxide, and hydroxyl radical, as well as to the release of other neutrophil-derived mediators $^{(2-5,16,17)}$. In order to explore the effects of antioxidant defences on the acute inflammation process in all paw tissues, the levels of antioxidant parameters were evaluated.

The GST (E.C. 2.5.1.18) are a multigene family of isoenzymes responsible for detoxification of xenobiotics in aerobic organisms. Endogenous substrates include the toxic products of tissue damage, including the hydroperoxide products of oxidative damage (including lipid peroxides), and aromatic xenobiotics. The present study determined that GST activity was inhibited by both ALA and DIC in CAR-induced paw tissues in which CAR significantly increased (Table 3). El Midaoui et al. ${ }^{(41)}$ reported that high-glucose feeding rapidly induced hypertension and that the plasma and aorta GST activities of rats were decreased by ALA administration.

Although oxygen intermediates are highly reactive and potentially cytotoxic, their formation is not typically deleterious to the cells, because these ROS are neutralised by endogenous enzymes and free radical scavengers. First, SOD catalysing the dismutation of superoxide anions $\left(\mathrm{O}_{2}^{-\cdot}\right)$ to $\mathrm{H}_{2} \mathrm{O}_{2}$ and $\mathrm{GSH}$-related enzymes preserving $\mathrm{GSH}$ status plays an important role in the antioxidant defence system by ensuring the degradation of these species into less harmful compounds ${ }^{(2,3,14,16,42)}$. From the present study (Table 4), we have established that ALA and DIC increase SOD activity, which was inhibited by CAR in rat paw tissues. The similar results were reported by Selvakumar et al. ${ }^{(43)}$ in cyclophosphamide-induced rat sperm and by Kokilavani et al. ${ }^{(44)}$ in arsenic-induced toxicity of rats. Separately, Khattab ${ }^{(45)}$ reported the importance of superoxide anion in CAR-induced acute inflammation and highlighted that the potential anti-inflammatory effects of SOD mimetic are mediated via the superoxide anion scavenging in acute inflammation. SOD destroys the highly reactive radical superoxide by converting it into the less reactive peroxide $\left(\mathrm{H}_{2} \mathrm{O}_{2}\right)$, which can be destroyed by a CAT reaction. CAT is a highly reactive enzyme, reacting with $\mathrm{H}_{2} \mathrm{O}_{2}$ to form water and molecular oxygen and can form methanol, ethanol, formic acid or phenols via donating hydrogen. In the present study (Table 4), we established that IND and DIC decreased, but all the doses of ALA increased further CAT activity, which was increased by CAR in rat paw tissues. On the other hand, it was reported by Selvakumar et al. ${ }^{(43)}$ that ALA has an increasing effect on the activity of the CAT enzyme in rats.

Separately, similar to SOD, we showed that GPx activity was elevated by one dose of DIC and IND, or 100 and $200 \mathrm{mg} / \mathrm{kg}$ doses of ALA, which was alleviated by CAR in rat paw tissues (Table 3). Decrease in the activity of GPX during CAR administration indicates the reduction in the levels of GSH and increase in the levels of peroxides. Moreover, the fact that arsenic decreased Se levels in rats $^{(31)}$, which acts as a cofactor for GPx, might be a reason for the decrease in the activity of GPx.

On the other hand, Chen et al. ${ }^{(46)}$ suggested that CAT stimulated the expression of mRNA and protein for cyclooxygenase- 2 in rat aortic smooth muscle cells, despite not affecting the expression of either mRNA or protein for cyclo-oxygenase-1. That is, CAT exerted a biphasic effect on PG synthesis and enhanced PG production by external administrations in small concentrations. This suggested that at small concentrations, CAT administration may cause inflammation as reflected by increased cyclooxygenase- 2 activity. One of the factors causing the formation of CAR-induced acute inflammation process is possibly an augmentation of CAT activity, which was ascertained in the results of the present experiment.

Reduced GSH having pleiotropic roles, including the maintenance of cells in a reduced state, serves as an electron donor for certain anti-oxidative enzymes (e.g. GPx) and the formation of conjugates with some harmful endogenous and xenobiotic compounds via catalysis of GST. The anti-inflammatory effects of ALA can be supported by GSH levels in CAR-induced rat paw tissues. Furthermore, treatment with ALA enhanced GSH level which had been decreased by CAR in the rat paws (Fig. 4). In other studies, it was shown that ALA increased GSH levels in arsenic-induced toxicity of rats ${ }^{(44)}$, cyclophosphamide-induced rat sperm ${ }^{(43)}$, ischaemia-reperfusion injury of rats ${ }^{(15)}$ and 2,4,6-trinitrobenzene sulphonic acidinduced gut inflammation of rats ${ }^{(36)}$. 
Since ALA raises intracellular GSH levels, it has been used for treating diseases in which oxidative stress plays a major role. On the other hand, GR indirectly participates in the protection of cells against oxidative stress. The enzymatic activities of GR have been investigated in various tissues under physiological and pathological conditions ${ }^{(47)}$. Table 3 shows that GR activity was activated by both IND and DIC in CAR-induced paw tissues in which CAR significantly inhibited. However, ALA has no effect on the GR activity.

A primary measure of oxidative damage in tissues is LPO, where thiobarbituric acid is measured as the index of LPO. The injection of the inflammation-inducing agent, CAR, considerably increases the levels of $\mathrm{LPO}^{(48)}$. In the present investigation, there is a significant increase in the levels of LPO in the paws of CAR-injected rats (Fig. 5). The increase in the levels of LPO is due to the increased release of $\mathrm{Fe}$ that is believed to be involved in the Fenton type of reaction. This 'free Fe' is considered as a potent enhancer of ROS formation, as exemplified by the reduction of $\mathrm{H}_{2} \mathrm{O}_{2}$ with the generation of highly aggressive hydroxyl radicals. However, administrations of CAR plus ALA, IND and DIC significantly $(P<0.01)$ alleviated the amount of LPO. Similar results related to effects of ALA on LPO have been reported by the literature ${ }^{(15,43,44)}$. In the present study, ALA pre-treatment significantly reversed the increase of lipid peroxide and the altered antioxidant status. The increase in LPO reported here may be the result of increased production of free radicals and/or a decrease in antioxidant status. ALA scavenges the singlet oxygen, $\mathrm{H}_{2} \mathrm{O}_{2}$ and hydroxyl radicals, and also chelates the ferrous ions involved in the production of hydroxyl radicals ${ }^{(21,22)}$.

MPx is an enzyme found primarily in azurophilic granules of neutrophils, which is used as a marker for tissue neutrophil content, and its inhibition implicates the presence of anti-inflammatory activity ${ }^{(37)}$. In the present study, we determined that MPx activity significantly $(P<0.05)$ increased in the paw at $5 \mathrm{~h}$ after CAR injection when compared with healthy rats (Fig. 3). Moreover, MPx activity was alleviated by 50, 100 and $200 \mathrm{mg} / \mathrm{kg}$ doses of ALA more than IND. On the other hand, DIC had no effect on the activity of MPx in CAR-injected rat paws. It was reported that the release of MPx from inflammatory cells is another indicator to evaluate the degree of inflammation, and anti-inflammatory drugs may also exert their effects via the inhibition of MPx pathways ${ }^{(41,47,49)}$. A variety of anti-inflammatory drugs depress the increases in MPx activity in the case of inflammation ${ }^{(49)}$. Our data show that ALA and IND significantly decreased MPX activity (Fig. 4). The effect of DIC on MPx activity is inconsistent ${ }^{(50)}$ because of variations in different tissues. Each molecule of ALA contains two atoms of sulphur (Fig. 1). Because of its high sulphur content, ALA can inactivate MPx activity in rat paws. The decrease in MPx activity in response to ALA could be linked to the sulphur present in its chemical structure. Interestingly, most of the non-steroidal anti-inflammatory drugs and other drugs contain a thiol group (e.g. D-penicillamine and tiopronin) and are widely used in the treatment of rheumatoid arthritis ${ }^{(51)}$ and related diseases. It was shown that ALA treatment was effective in improving tissue LPO, and MPX activity increased and decreased GSH levels in 2,4,6-trinitrobenzene sulphonic acid-induced gut inflammation and ischaemia-reperfusion injury in rats ${ }^{(15,52)}$.

A growing body of evidence suggests that sustained production of NO resulting from up-regulation of the inducible isoform of NOS after CAR injection may cause an inflammatory response in rat paws. It is well established that iNOS levels under normal physiological conditions are low; however, the administration of CAR causes the induction of $\operatorname{iNOS}^{(53,54)}$.

In the present study, it was demonstrated that CAR administration in rats resulted in significant increases in iNOS levels in paws which were attenuated by ALA pre-treatment (Table 5). Similarly, it was reported that ALA alleviated the activity of $\operatorname{iNOS}^{(24)}$. In addition to ROS, excessive production of reactive nitrogenous species, especially NO through the activation of the constitutive as well as the expression of iNOS, has been shown to play an important role in various models of inflammation ${ }^{(3,4,11)}$. It has been also widely accepted that NO produced by iNOS is cytotoxic ${ }^{(3,18,55,56)}$. In view of these results, it can be suggested that ALA is a cytoprotective compound.

The molecular regulation of iNOS expression resulting in excessive amounts of NO released in paws is a complex event and requires the transcription factor $\mathrm{NF}-\kappa \mathrm{B}$. It has been shown that down-regulation of NF- $\mathrm{B}$ with antioxidants resulted in decreases in the amount of NO released in the circulation, a treatment effect attributed to the reduction in iNOS expression ${ }^{(57)}$. Another explanation for the reduction in NO levels in paws might be due to the direct scavenging effect of NO by the sulphydryl groups of ALA $^{(23)}$. It has been demonstrated that oxidative stress up-regulates and antioxidants down-regulate the pleiotropic transcription NF- $\kappa \mathrm{B}$, a DNA-binding protein that induces the expression of cytokines and vascular adhesion molecules ${ }^{(57)}$. The ability of ALA to inhibit the activation of NF-кB has been demonstrated with human T-cells exposed to TNF- $\alpha$ or phorbol-12-myristate-13-acetate or cultured aortic endothelial cells challenged with advanced glycation end products. Cho et al. ${ }^{(58)}$ showed that ALA decreased activations of $\mathrm{NF}-\kappa \mathrm{B}$ and pro-inflammatory chemical mediators, such as IL- 4 and IL- 5 in BAL fluids and ovalbumin-specific IgE. Similarly, Zhang \& Frei $^{(59)}$ reported that ALA may also affect NF-кB-dependent expression of many other inflammatory genes, such as IL-1 and IL-6, a tissue factor and TNF- $\alpha$ in numerous cell types. These investigations suggest that the functional mechanism underlying the therapeutic efficacy of ALA as an antioxidant on initiation and progression of various inflammatory diseases may be related to inhibition of NF- $\kappa$ B activation 
through decreased oxidative stress and subsequent reduction in pro-inflammatory chemical mediators.

In the chronic inflammation experiment, ALA significantly inhibited the weight of the cotton pellets inserted under the skin of rats. The effects of ALA, IND and DIC on cotton pellet-induced granuloma in rats are shown in Table 2. At doses of 50, 100 and $200 \mathrm{mg} / \mathrm{kg}$, ALA as well as DIC and IND $(25 \mathrm{mg} / \mathrm{kg})$ inhibited markedly $(P<0 \cdot 01)$ granuloma formation surrounding the pellets compared with the control group. ALA $(200 \mathrm{mg} / \mathrm{kg})$ produced a maximum inhibition of $70.6 \%$, while 50 and $100 \mathrm{mg} / \mathrm{kg}$ of ALA produced 67.7 and $68.9 \%$ inhibition in granuloma weight, respectively. IND and DIC significantly decreased the weight of implanted cotton pellets 83.8 and $76.1 \%$ in comparison with the control group, respectively.

It is known that inflammatory granuloma is a typical response of a chronic inflammatory process, and it has been established that the dry weight of the pellets is well correlated with granulomatous tissue. The cotton pellet granuloma method is frequently used to investigate the chronic phase of inflammation ${ }^{(2-5,8,60)}$. The anti-proliferative potency of IND and DIC was higher than that of ALA in the cotton pellet-induced granuloma test. Little data have been reported about mediators of chronic inflammation. However, the chronic inflammation model, induced by subcutaneous implantation of foreign bodies, is used commonly in experiments. Chronic inflammation starts with the occurrence of proliferative cells. These cells can be spread or can form a granuloma tissue. Inflammatory granuloma tissue is a typical example of chronic inflammation ${ }^{(60)}$. Granuloma formation is initialised by an antigen (for example, a cotton pellet). The cotton pellet stimulates the immune system, antibodies and the production of IL. This stimulation results with the proliferation of lymphocytes and the formation of granulation tissue over the pellets. Non-steroidal anti-inflammatory drugs and ulcers reduce granuloma tissue that is formed with cellular reactions by inhibiting granulocyte infiltration, while glucocorticoids do it by inhibiting fibrosis and macrophage functions.

It was reported that ALA on initiation and progression of various inflammatory diseases might be related to the inhibition of NF- $\mathrm{B}$ activation through decreased oxidative stress and subsequent reduction in pro-inflammatory chemical mediators ${ }^{58,59)}$. Antioxidants have various mechanisms such as prevention of chain initiation, binding of transition metal ion catalysts, decomposition of peroxides, prevention of continued hydrogen abstraction and radical scavenging $^{(3,5,17)}$. In the present study, ALA (1, 2.5 and $5 \mathrm{mg} / \mathrm{ml})$, ascorbic acid $(1 \mathrm{mg} / \mathrm{ml})$ and Trolox $(1 \mathrm{mg} / \mathrm{ml})$ after $44 \mathrm{~h}$ incubation with linoleic acid emulsion are also summarised as inhibition (\%) in Table 6. Trolox and ascorbic acid were used as positive controls for the hydrophilic antioxidants. In general, the oxidation of linoleic acid was inhibited by ALA, ascorbic acid and Trolox, as observed when compared with the control.
However, the antioxidant activities of all the doses of ALA and Trolox except for ascorbic acid in comparison with the control were statistically significant $(P<0.05$ and 0.01). The $1,2.5$ and $5 \mathrm{mg} / \mathrm{ml}$ doses of ALA exhibited potent antioxidant activities with $34.9,58.9$ and $79 \cdot 1 \%$ inhibition of linoleic acid peroxidation, respectively. However, the antioxidant activities of ALA were lower than that of Trolox. The present results showed that ALA has a strong anti-oxidative potential (Table 6). Given this, it must be considered that the antioxidant potential of ALA might play an important role in the prevention of inflammation processes in rats.

In conclusion, the current results showed that tested agents (ALA, IND and DIC) reduced paw volume, at a smaller magnitude in response to ALA than IND and DIC. The level of antioxidant system enzymes (GST, GPx, GR, SOD and CAT, MPx, iNOS) and levels of GSH or LPO were adversely affected by oedema induction. ALA ameliorated the adverse effects of oedema on these enzymes. In addition, ALA exhibited an anti-inflammatory effect on the cotton pellet-induced chronic inflammation in rats. The anti-inflammatory properties of ALA which has a strong anti-oxidative potency could be related to its positive effects on the antioxidant system in a variety of rat tissues. In the light of the present results, we can suggest that ALA, an over-the counter drug with no side effects, possesses a dual beneficial effect, such that it might improve the prognosis of acute and chronic inflammatory diseases when used alone and/or combined with a known anti-inflammatory agent.

\section{Acknowledgements}

None of the authors has a commercial interest, financial interest and/or other relationship with manufacturers of pharmaceuticals, laboratory supplies and/or medical devices or with commercial providers of medically related services. F. O. was the main moderator of the study. F. O., M. H., F. A. and Y. B. performed the biochemical investigation in the present study. Z. H., E. C. and H. S. performed the pharmacologic investigations in the present study. H. A. contributed in pharmacological paw experiments as an orthopaedist. A. C. contributed in both writing period and statistical analyses.

\section{References}

1. Albayrak A, Uyanik H, Odabasoglu F, et al. (2010) The effects of diabetes and/or polymicrobial sepsis on the status of antioxidant enzymes and pro-inflammatory cytokines on heart, liver, and lung of ovariectomized rats. J Surg Res (In the Press).

2. Halici Z, Dengiz GO, Odabasoglu F, et al. (2007) Amiodarone has anti-inflammatory and anti-oxidative properties: an experimental study in rats with carrageenan-induced paw edema. Eur J Pharmacol 566, 215-221. 
3. Tanas S, Odabasoglu F, Halici Z, et al. (2010) Evaluation of anti-inflammatory and antioxidant activities of Peltigera rufescens lichen species on acute and chronic inflammation models. J Nat Med 64, 42-49.

4. Salvemini D, Wang ZQ, Wyatt P, et al. (1996) Nitric oxide: a keymediator in the early and late phase of carrageenaninduced rat paw inflammation. $\mathrm{Br} J$ Pharmacol 118, $829-838$

5. Odabasoglu F, Halici Z, Cakir A, et al. (2008) Beneficial effects of vegetable oils (corn, olive and sunflower oils) and $\alpha$-tocopherol on anti-inflammatory and gastrointestinal profiles of indomethacin in rats. Eur J Pharmacol 591, 300-306.

6. Jain NK, Kulkami SK \& Singh A (2001) Role of cysteinyl leukotrienes in nociceptive and inflammatory conditions in experimental animals. Eur J Pharmacol 415, 85-94.

7. Kumtepe Y, Odabasoglu F, Karaca M, et al. (2010) Protective effects of telmisartan on ischemia/reperfusion injury of rat ovary: biochemical and histopathologic evaluation. Fertil Steril 93, 1299-1307.

8. Suleyman H, Odabasoglu F, Aslan A, et al. (2003) Antiinflammatory and antiulcer effects of aqueous extract of Lobaria pulmonaria. Phytomedicine 10, 552-557.

9. Hosseinzadeh H, Ramezani M \& Salmani GH (2000) Antinociceptive, anti-inflammatory and acute toxicity of Zataria multiflora Boiss. extracts in mice and rats. J Ethnopharmacol 73, 379-385.

10. Kapu SD, Ngwai YB, Kayode O, et al. (2001) Anti-inflammatory, analgesic antilymphocytic activities of the aqueous extract of Crinum giganteum. J Ethnopharmacol 78, 7-13.

11. Handy RLC \& More PK (1998) A comparison of the effects of L-NAME, 7-NI and L-NIL on carrageenan-induced hind paw oedema and NOS activity. Br J Pharmacol 123, 1119-1126.

12. Odabasoglu F, Karakus B, Bayir Y, et al. (2006) Effects of methanol extract of Lobaria pulmonaria on glutathione $S$-transferase activity and gastric damages in rats. Abstracts from XIXth International Symposium on Medicinal Chemistry. Drug Future 31, 168.

13. Moreira PI, Harris PLR, Zhu XW, et al. (2007) Lipoic acid and $n$-acetyl cysteine decrease mitochondrial-related oxidative stress in Alzheimer disease patient fibroblasts. $J$ Alzheimers Dis 12, 195-206.

14. Cadirci E, Altunkaynak BZ, Halici Z, et al. (2009) Alphalipoic acid as a potential target for the treatment of lung injury caused by cecal ligation and puncture-induced sepsis model in rats. Shock 33, 479-484.

15. Sehirli O, Sener E, Cetinel U, et al. (2008) Alpha-lipoic acid protects against ischemia-reperfusion injury in rats. Clin Exp Pharmacol 35, 249-255.

16. Karaca M, Odabasoglu F, Kumtepe Y, et al. (2009) Protective effects of erythropoietin on ischemia/reperfusion injury of rat ovary. Eur J Obstet Gynecol Reprod Biol 144, 157-162.

17. Dengiz GO, Odabasoglu F, Halici Z, et al. (2007) Gastroprotective and antioxidant effects of montelukast on indomethacin-induced gastric ulcer in rats. J Pharmacol Sci $\mathbf{1 0 5}$, 94-102.

18. Nishida K, Ohta Y \& Ishiguro I (1998) Contribution of NO synthases to neutrophil infiltration in the gastric mucosal lesions in rats with water immersion restraint stress. FEBS Lett 425, 243-248.

19. Cadirci E, Oral A, Odabasoglu F, et al. (2010) Atorvastatin reduces tissue damage in rat ovaries subjected to torsion and detorsion: biochemical and histopathologic evaluation. Naunyn Schmiedebergs Arch Pharmacol 381, 455-466.

20. Huong DTT \& Ide T (2008) Dietary lipoic acid-dependent changes in the activity and mRNA levels of hepatic lipogenic enzymes in rats. Br J Nutr 100, 79-87.
21. Bilska A \& Wlodex L (2005) Lipoic acid - the drug of future? Pharmacol Rep 57, 570-577.

22. Odabasoglu F (2006) Alfa-lipoik asit (Alpha lipoic-acid). Pharma Sark 1, 12-15.

23. Biewenga GP, Haene GR \& Bast A (1997) The pharmacology of the antioxidant lipoic acid. Gen Pharmacol 29, 315-331.

24. Hurdag C, Ozkara H, Citci S, et al. (2005) The effects of alpha-lipoic acid on nitric oxide synthetase dispersion in penile function in streptozotocin-induced diabetic rats. Int J Tissue React 27, 145-150.

25. Malinska D \& Winiarska K (2005) Lipoic acid: characteristics and therapeutic application. Postepy Hig Med Dosw 59, $535-543$.

26. Demir U, Demir T \& Ilhan N (2005) The protective effect of $\alpha$-lipoic acid against oxidative damage in rabbit conjunctiva and cornea exposed to ultraviolet radiation. Ophthalmologica 219, 49-53.

27. Patrick L (2000) Nutrients and HIV: part three $-N$-acetylcysteine, alpha-lipoic acid, L-glutamine, and L-carnitine. Altern Med Rev 5, 290-305.

28. Wenzel U, Nickel A \& Daniel H (2005) $\alpha$-Lipoic acid induces apoptosis in human colon cancer cells by increasing mitochondrial respiration with a concomitant $\mathrm{O}_{2}^{-}$-generation. Apoptosis 10, 359-368.

29. Canadian Council on Animal Care (1993) Guide to the Care and Use of Experimental Animals, vol. I, 2nd ed. Ottawa, ON: Canadian Council on Animal Care/Bradda Printing Services, Inc.

30. Habig WH \& Jakoby WB (1981) Assays for differentiation glutathione-S-transferase. Method Enzymol 77, 398-405.

31. Lawrence RA \& Burk RF (1976) Glutathione peroxidase activity in selenium-deficient rat liver. Biochem Biophys Res Commun 71, 952-958.

32. Carlberg I \& Mannervik B (1985) Glutathione reductase. Method Enzymol 113, 484-490.

33. Aebi H (1984) Catalase. Method Enzymol 105, 121-126.

34. Sun Y, Larry WO \& Ying L (1988) A simple method for clinical assay of superoxide dismutase. Clin Chem $\mathbf{3 4}$, 497-500.

35. Knowles RG, Salter M, Brooks SL, et al. (1990) Anti-inflammatory glucocorticoids inhibit the induction by endotoxin of nitric oxide synthase in the lung, liver and aorta of the rat. Biochem Biophys Res Commun 172, 1042-1048.

36. Feelisch M \& Noack EA (1987) Correlation between nitric oxide formation during degredation of organic nitrates and activation of guanylate cyclise. Eur J Pharmacol 139, 19-30.

37. Bradley PP, Priebat DA, Christensen RD, et al. (1982) Measurement of cutaneous inflammation: estimation of neutrophil content with an enzyme marker. $J$ Invest Dermatol 78, 206-209.

38. Sedlak J \& Lindsay RH (1968) Estimation of total, proteinbound, and nonprotein sulfhydryls groups in tissue with Ellman's reagent. Anal Biochem 25, 192-205.

39. Ohkawa H, Ohishi H \& Yagi K (1979) Assay for lipid peroxide in animal tissues by thiobarbutiric acid reaction. Anal Biochem 95, 351-358.

40. Odabasoglu F, Aslan A, Cakir A, et al. (2005) Antioxidant activity, reducing power and total phenolic content of some lichen species. Fitoterapia 76, 216-219.

41. El Midaoui A, Elimadi A, Wu L, et al. (2003) Lipoic acid prevents hypertension, hyperglycemia, and the increase in heart mitochondrial superoxide production. Am J Hypertens 16, $173-179$.

42. Halici Z, Karaca M, Keles ON, et al. (2008) Protective effects of amlodipine on ischemia-reperfusion injury of rat ovary: biochemical and histopathologic evaluation. Fertil Steril 90, $2408-2415$. 
43. Selvakumar E, Prahalathan C, Sudharsan PT, et al. (2006) Chemoprotective effect of lipoic acid against cyclophosphamide-induced changes in the rat sperm. Toxicology 217, 71-78.

44. Kokilavani V, Devi MA, Sivarajan K, et al. (2005) Combined efficacies of DL- $\alpha$-lipoic acid and meso 2,3-dimercaptosuccinic acid against arsenic induced toxicity in antioxidant systems of rats. Toxicol Lett 160, 1-7.

45. Khattab M (2006) Tempol, a membrane-permeable radical scavenger, attenuates peroxynitrite- and superoxide anionenhanced carrageenan-induced paw edema and hyperalgesia: a key role for superoxide anion. Eur J Pharmacol 548, $167-173$.

46. Chen G, Kamal M, Hannon R, et al. (1998) Regulation of cyclo-oxygenase gene expression in rat smooth muscle cells by catalase. Biochem Pharmacol 55, 1621-1631.

47. Shacter E, Lopez RL \& Pati S (1991) Inhibition of myeloperoxidase $-\mathrm{H}_{2} \mathrm{O}_{2}-\mathrm{Cl}$-system of neutrophils by indometahcin and other non-steroidal anti-inflammatory drugs. Biochem Pharmacol 41, 975-984.

48. Govindarajan R, Vijayakumar M, Rao CV, et al. (2007) Antiinflammatory and antioxidant activities of Desmodium gangeticum fractions in carrageenan-induced inflamed rats. Phytother Res 21, 975-979.

49. Paino IMM, Ximenes VF, Fonseca LM, et al. (2005) Effect of therapeutic plasma concentrations of non-steroidal antiinflammatory drugs on the production of reactive oxygen species by activated rat neutrophils. Braz J Med Biol Res 38, 543-551.

50. Matsui H, Murata Y, Kobayashi F, et al. (2001) Diclofenacinduced gastric mucosal fluorescence in rats. Digest Dis Sci 46, 338-344.

51. Bonta IL, Parnham MJ, Vincent JE, et al. (1980) 5 Anti-rheumatic drugs: present deadlock and new vistas. In Progress in
Medicinal Chemistry, pp. 185-273 [GP Ellis and GB West, editors]. North-Holland/Elsevier: Amsterdam.

52. Kolgazi M, Jahovic, Yüksel M, et al. (2006) $\alpha$-Lipoic acid modulates gut inflammation induced by trinitrobenzene sulfonic acid in rats. J Gastroen Hepatol 22, 1859-1865.

53. Cuzzocrea S, Bruscoli S, Crisafulli C, et al. (2007) Estrogen receptor antagonist fulvestrant inhibits the anti-inflammatory effect of glucocorticoids. Mol Pharmacol 71, 132-144.

54. Hurdag C, Uyaner I, Gurel E, et al. (2008) The effect of alpha lipoic acid on NOS dispersion in the lung of streptozotocin-induced diabetic rats. J Diabetes Complications 22, $56-61$.

55. Odabasoglu F, Suleyman H, Aslan A, et al. (2005) The effects of diffractaic acid on MPx and NOS enzymes activities in indomethacine-induced ulcer in rats. Adv Mol Med 1, 402-403.

56. Jean YH, Chen WF, Duh CY, et al. (2008) Inducible nitric oxide synthase and cyclooxygenase- 2 participate in antiinflammatory and analgesic effects of the natural marine compound lemnalol from Formosan soft coral Lemnalia cervicorni. Eur J Pharmacol 578, 323-331.

57. van den Berg R, Haenen GR, van den Berg H, et al. (2001) Transcription factor NF- $\mathrm{KB}$ as a potential biomarker for oxidative stress. Br J Nutr 86, S121-S127.

58. Cho YS, Lee J, Lee TH, et al. (2004) $\alpha$-Lipoic acid inhibits airway inflammation and hyperresponsiveness in a mouse model of asthma. J Allergy Clin Immunol 114, 429-435.

59. Zhang WJ \& Frei B (2001) $\alpha$-Lipoic acid inhibits TNF- $\alpha$ induced NF- $\alpha \mathrm{B}$ activation and adhesion molecule expression in human aortic endothelial cells. FASEB J 15, 2423-2432.

60. Olajide OA, Makinde JM \& Awe SO (1999) Effects of the aqueous extract Bridella ferruginea stem bark on carrageenan induced oedema and granuloma tissue formation in rats and mice. J Ethnopharmacol 66, 113-117. 